\title{
Cultura política e política de massas: Aproximações entre integralismo e neointegralismo*
}

DOI: 10.15175/1984-2503-202113302

\author{
João Henrique Zanelatto*
}

\begin{abstract}
Resumo
A Ação Integralista Brasileira foi criada em São Paulo por Plínio Salgado em 1932. Foi um movimento de caráter conservador e ultranacionalista que rapidamente se expandiu por todo o território nacional. Contribuiu para esse rápido crescimento a constituição de rituais símbolos, que eram materializados por meio de desfiles nas praças e nas ruas das cidades. Assim, o objetivo deste escrito é demonstrar como as ruas das cidades se constituíram em um espaço para propaganda da Ação Integralista Brasileira, além de mostrar como esses espaços eram utilizados para a materialização da simbologia e dos rituais integralistas. Pretende-se, também, apontar para a rearticulação da AIB no pós-45 e a conexão desse movimento com o neointegralismo no século XXI configurando o integralismo como uma cultura política.
\end{abstract}

Palavras-chave: cultura política; integralismo; neointegralismo.

Cultura política y política de masas: aproximaciones entre integralismo y neointegralismo

\section{Resumen}

La Ação Integralista Brasileira fue creada en São Paulo por Plínio Salgado en 1932. Constituyó un movimiento de carácter conservador y ultranacionalista que se expandió rápidamente por todo el territorio brasileño. A este rápido crecimiento contribuyó la constitución de rituales simbólicos que se materializaron a través de desfiles en las plazas y calles de las ciudades. El objetivo de este trabajo es mostrar que las calles de las ciudades se convirtieron en un espacio de propaganda de la Ação Integralista Brasileira y señalar que estos espacios se utilizaron para materializar la simbología y los rituales integrales. Así mismo, se pretende hacer visible la rearticulación de la AIB después de 1945 y la conexión de este movimiento con el neointegralismo en el siglo $X X I$, lo que lleva a la configuración del integralismo como cultura política.

Palabras clave: cultura política; integralismo; neointegralismo.

\footnotetext{
* Este artigo faz parte de um projeto mais amplo, que aborda as conexões entre Integralismo e neointegralismo, suas relações com outros grupos de extrema direita nacionais e internacionais e partidos políticos. O projeto é financiado pelo CNPq.

** Doutor em História, docente do Curso de História e do Programa de Pós-Graduação em Desenvolvimento Socioeconômico da Universidade do Extremo Sul Catarinense. Líder do Grupo de Pesquisa "História Econômica e Social de Santa Catarina". E-mail: jhz@unesc.net.

http://lattes.cnpq.br/9654723907325486. (․) https://orcid.org/0000-0002-1754-1001.
}

Recebido em 20 de janeiro de 2021 e aprovado para publicação em 08 de junho de 2021. 
Passagens: Revista Internacional de História Política e Cultura Jurídica

Rio de Janeiro: vol. 13, ${ }^{0}$ 3, setembro-dezembro, 2021, p. 419-445.

\title{
Culture and mass politics: Connections between Integralism and Neo-Integralism
}

\begin{abstract}
The Ação Integralista Brasileira [Brazilian Integralist Action] movement was founded in São Paulo by Plínio Salgado in 1932. Conservative and ultra-nationalist in character, it rapidly expanded across the entirety of Brazil, with one of the drivers of its success the constitution of symbolic rituals to materialize by means of parades in urban squares and streets. The aim of this article is therefore to demonstrate how Brazil's city streets served as a space for the AIB's propaganda, as well as revealing how these spaces were used to materialize Integralist symbology and rituals. The article also aims to outline the AIB's reorganization post-1945 and to highlight the movement's connection with Neo-Integralism in the twenty-first century, identifying Integralism as a political culture.
\end{abstract}

Keywords: political culture; Integralism; Neo-Integralism.

\section{Culture politique et politique de masses : les rapprochements entre intégralisme et néointégralisme}

\section{Résumé}

L'Action intégraliste brésilienne a été créée en 1932 à São Paulo par Plínio Salgado. II s'agit d'un mouvement de type conservateur et ultranationaliste qui s'est rapidement étendu à tout le territoire national. Cette croissance rapide a été alimentée par la constitution de rituels symboliques matérialisés par des défilés sur les places et dans les rues des villes. L'objectif de cet article est ainsi de montrer comment les rues sont devenues un espace de propagande de l'Action intégraliste brésilienne, mais également de quelle manière ces espaces étaient utilisés pour la matérialisation de la symbologie et des rituels intégralistes. II s'agira également de d'analyser la réarticulation de l'AIB d'après-guerre et la connexion entre ce mouvement et le néointégralisme du $X X I^{\mathrm{e}}$ siècle, faisant ainsi de l'intégralisme une culture politique.

Mots-clés : culture politique ; intégralisme ; néointégralisme.

\section{巴西政治文化与大众政治：整合主义与新整合主义之间的近似}

\section{摘要}

巴西的整合主义运动(Ação Integralista Brasileira -AIB) 由普利尼奥·索尔加多(Plínio Salgado) 于 1932 年在圣保罗创立。它是一场保守和极端民族主义的运动，迅速扩展到整个国家领土。通过城市广场和街道上的游 行，它们把象征性仪式具体化，促成了巴西整合运动的快速成长。本文的目的是展示城市街道如何被转化为宣传 巴西整合主义行动的空间，这些空间如何被利用来展现整合主义的象征性符号与仪式。本文指出，AIB 在 1945以后被重新表述，它与

世纪出现的新整合主义有密切的联系。在此过程中，巴西整合主义被转变为一种政治文化。

关键词：政治文化；整体主义；新整合主义。 


\section{Introdução}

Desde 2013, as praças e as ruas das cidades brasileiras foram/vem sendo tomadas por milhares de cidadãos que utilizaram as mais variadas maneiras para exprimir ou expor suas reinvindicações. Nessas mobilizações, observou-se uma diversidade de grupos provenientes de várias correntes ideológicas, que se aproveitaram do momento para provocar violência, materializar seus ideais, ritos, símbolos etc., e até propor uma intervenção militar. Na história republicana brasileira, é possível observar como as ruas e praças das cidades foram utilizadas pelos vários setores da sociedade, seja de direita ou de esquerda, para reivindicar, protestar ou para difusão de seus rituais e simbologia, visando à arregimentação de novos adeptos.

São exemplos do exposto as mobilizações da população, no início do século, provocadas pela Revolta da Vacina; as greves; a Marcha dos Dezoito do Forte de Copacabana; os fascistas, os nazistas, os integralistas e os comunistas, na década de 1930; a campanha do petróleo, em 1954, que levou à criação da Petrobrás; o pré-golpe de 1964; a marcha da família, liderada pela igreja; a campanha das Diretas, em 1984; os CarasPintadas, em 1992, que pediam o impeachment do então presidente Fernando Collor de Mello; e as recentes mobilizações que vem ocorrendo desde 2013.

Assim, em um contexto em que os setores conservadores ${ }^{1}$ de nossa sociedade têm saído do "armário" e tomado as ruas e as praças das cidades, fazendo explicitamente o discurso e a defesa da volta dos regimes autoritários, consideramos relevante fazer uma reflexão, mesmo que breve, sobre os momentos em que esses setores da sociedade estiveram em evidência, especialmente a Ação Integralista Brasileira e sua conexão com o neointegralismo' (BERTONHA, 2016; GONÇALVES; CALDEIRA NETO, 2020). Portanto, o escrito aborda a Ação Integralista Brasileira (AIB), utilizando-se das praças e das ruas das cidades para a manifestação de seus rituais e simbologias, cujos aspectos - discursos,

\footnotetext{
1 Entre os analistas deste novo fenômeno é possível encontrar uma desorientação histórica, conceitual e doutrinaria. Isso ocorre em razão do caráter ambíguo da categoria conservadorismo e direita, pois não existe apenas um conservadorismo e uma direita, mas sim diversos e distintos conservadorismos e direitas. São fenômenos históricos e sociais, sofrem mutação temporalmente e culturalmente. Pode-se considerar como princípios que norteiam o conservadorismo e a direita: ordem, a autoridade, a hierarquia, a religião, a tradição, a família, a pátria, a responsabilidade individual e social, para alguns a economia de mercado...
} 
doutrina e práticas integralistas - permaneceram, foram readaptados e estão presentes entre os neointegralistas.

Destarte a pretensão do escrito foi/é contribuir no debate sobre o integralismo dos anos de 1930 com seus rituais, símbolos e propaganda, e sua conexão com o neointegralismo e assim, entendendo o integralismo como uma cultura política. Desse modo, este escrito se fundamentou na renovada história política' (REMOND, 2003) e no conceito de cultura política (BERSTEIN, 1998; MOTTA, 2009) para compreensão das conexões entre o integralismo e o neointegralismo. Destarte faz-se uma breve digressão sobre o processo de construção do conceito.

A força do conceito de Cultura Política deve-se à hegemonia do paradigma culturalista ocorrido no final do século XX. O conceito foi sendo construído ao longo do século $X X$, mas seus formuladores buscam inspiração em autores de época anterior. Destaca-se Alixis de Tocqueville, com seu livro Democracia na América de 1835. Tocqueville desenvolveu ideia de que a força dos EUA não vinha somente das instituições, mas dos hábitos e costumes. Para Tocqueville, o funcionamento de sistemas políticos dependia de fatores culturais. $O$ conceito teve também influência da historiografia e da filosofia alemã do século XIX. Desenvolveram o conceito de Kultur - cada povo tinha uma cultura e alguns eram culturalmente superiores. Assim, em seus usos iniciais o conceito implicava em certa hierarquização, alguns povos possuem cultura política, eram mais avançados, outros ainda não a possuíam, ou apenas em forma inferior (MOTTA, 2009).

$\mathrm{Na}$ academia o conceito ${ }^{2}$ começou a ser utilizado nas décadas de 1950 e 1960, em especial pelos cientistas sociais Norte Americanos - Gabriel Almond e Sidney Verba que foram influenciados pela psicologia e a sociologia. Uma questão que motivou esses estudos foi a preocupação com o campo "democrático" - contexto da guerra fria. Almond e Verba criaram uma tipologia para enquadrar as diferentes formas de cultura política - Três tipos básicos: a) cultura política paroquial; b) cultura política da sujeição; c) cultura política participativa (esta última considerada etapa superior). Apontavam para a perspectiva de uma

\footnotetext{
2 No Brasil o conceito apareceu durante o Estado Novo, com criação da Revista de Cultura Política e posteriormente apropriado pelo PCB em 1947.
} 
cultura política nacional - cultura política democrática como etapa superior e referência a ser seguida (MOTTA, 2009).

Nas décadas de 1950 - 1970 - preocupação com processos econômicos e sociais pouco interesse pela cultura política por parte dos historiadores. As reflexões em torno da cultura ganharam espaço na história no contexto de renovação da história política na década de 1980.

$\mathrm{Na}$ França na década de 1990, os historiadores S. Berstein e J. F. Sirinelli influenciados pela antropologia enfatizam as diferenças dentro do espaço nacional e apontaram para as pluralidades das culturas políticas e neste sentido teceram a crítica ao modelo Norte Americano. Entretanto, autores defendem a possibilidade de uso do conceito nas duas versões - cultura política nacional e cultura política plural (MOTTA, 2009).

Portanto, o conceito de cultura política utilizado nesse escrito está em conexão com a historiografia francesa. Dessa maneira, conforme Serge Berstein (1998) a cultura política seria a expressão pela qual podemos denominar os códigos e conjuntos de referentes formalizados no seio de um partido, de uma comunidade ou uma tradição política. Não devemos, de acordo com o autor, entender a cultura política como uma ideologia ou um conjunto de tradições, mas como em um dado momento da história e em certo dado país possui caráter plural, momento no qual as representações passaram a adquirir um papel de importância na sua definição.

A cultura política aparece em suas diversas manifestações, como a linguagem comum simplificada (da qual o rito é a forma mais sumária) dos membros de uma formação, que desse modo fazem profissão de ideologia sem precisar necessariamente exprimila explicitamente, mas com a certeza de serem facilmente compreendidos por todos os membros do grupo (BERSTEIN, 2003, p. 89).

Nessa esteira, evidenciamos o conceito de Cultura Política definido por (MOTTA, 2009 , p. 21) "[...] conjunto de valores, tradições, práticas e representações políticas partilhadas por determinado grupo humano, que expressa uma identidade coletiva e fornece leituras comuns do passado, assim como fornece inspiração para projetos políticos direcionados ao futuro". A representação é entendida como "um conjunto que inclui ideologia, linguagem, memória, imaginário e iconografia, e mobilizam, portanto, mitos, símbolos, discursos, vocabulários e uma rica cultura visual (cartazes, emblemas, caricaturas, cinema 
fotografia, bandeiras etc.)" (MOTTA, 2009, p. 21-22). Destarte, a cultura política pode mobilizar sentimentos (paixões, esperanças e medos), valores (moral, honra, solidariedade), fidelidade às tradições (família, nação, líderes).

Com essa perspectiva o conceito permite uma compreensão rica e sofisticada do comportamento político. Portanto, entende-se o integralismo como uma cultura política, ou seja, "um conjunto coerente em que todos os elementos estão em estreita relação uns com os outros" (BERSTEIN, 1998, p. 350).

A AIB foi criada em São Paulo sob a liderança do jornalista Plínio Salgado, em 1932. Movimento político, inspirado nos fascismos europeus, mas com singularidades próprias' (TRINDADE, 2016). Em 1937, a AIB já contava com mais de um milhão de adeptos. Esse crescimento pode ser percebido quando fazemos um comparativo entre o número de inscrições efetuadas de 1933 a 1937. Conforme o Monitor Integralista, ao final de 1933, a AIB contava com 20 mil inscritos; em 1934, passou para 180 mil; em 1935, o número saltou para 380 mil; em 1936, chegou a 918 mil. Finalmente, em 1937, já havia mais de um milhão de pessoas inscritas' (MONITOR INTEGRALISTA, ano V, n. 22, p. 4, 7 out. 1937). Mesmo que esses dados contenham certo grau de exagero e possam ser contestados, a literatura sobre o integralismo aponta para um número expressivo de adeptos ${ }^{3}$.

\section{O fascismo e o controle das massas}

Um dos objetivos deste artigo é demonstrar como as ruas das cidades constituíram-se em um espaço para propaganda e publicidade da Ação Integralista Brasileira, mostrar como esses espaços eram utilizados para a manifestação da simbologia e dos rituais integralistas: as grandes concentrações, os desfiles, o civismo, o disciplinamento, o nacionalismo de farda, as demonstrações de patriotismo. Esse tipo de manifestação se refere a uma dimensão política da cidade, evidenciada nas grandes mobilizações civis, "[...] quando o espaço público deixa de ser apenas cenário da circulação do dia a dia para assumir o caráter de civitas", (ROLNIK, 2004, p. 24-25). Nessas manifestações, sejam elas "[...] passeata, comícios ou

\footnotetext{
${ }^{3}$ Segundo (GERTZ, 1984, p. 17) a AIB possuía 600.000 inscritos em todo o Brasil. Já (ARAÚJO, 1988, p. 25) ao colocar o integralismo como o primeiro partido de massas, destaca que, em 1935, havia 1.123 grupos organizados em 538 municípios, com cerca de 400.000 adeptos distribuídos de Norte a Sul do País.
} 
barricada, a vontade dos cidadãos desafia o poder urbano através da apropriação simbólica do terreno público", (BERTONHA, 2003, p. 66). Nesses momentos "é que as muralhas invisíveis que regulam a cidade, mantendo cada coisa no seu lugar e comprimindo a multidão do dia a dia, salientavam-se pela ausência" (BOLLE, 1994, p. 227).

Assim, nos primeiros anos da década de 1930, as ruas das cidades eram tomadas pelos integralistas, que realizavam desfiles e passeatas (dezenas, centenas, milhares de homens), tornando-se um dos principais instrumentos de propaganda do movimento. Ressalta-se a importância dada ao misticismo e à simbologia em todos os rituais integralistas, não se diferenciando de seus irmãos europeus.

Pouco importava se o símbolo máximo do integralismo era o sigma, o fascismo, o fascio littorio, e o do nazismo a suástica "Embora não fossem visualmente iguais, o objetivo de ambos era o mesmo: corporificar a ideologia do movimento e colaborar na sua difusão e popularidade" (BOLLE, 1994, p. 227). Walter Benjamin (1975, p. 33) definiu os conceitos de arte e de cultura do fascismo ao dizer: "A arte fascista é uma arte de propaganda. Portanto, ela é executada para as massas. A propaganda fascista precisa penetrar a vida social por inteiro. A arte fascista, portanto, não é executada apenas para as massas, mas também pelas massas".

Por isso, a cultura fascista constituiu-se em um conjunto de atividades organizadas para o controle das massas. A cultura fascista, procurando garantir seu domínio sobre o capital, é a arte de dominar as massas. Seguindo uma lógica própria, o fascismo procura "[...] encobrir as contradições sociais, desviar dos conflitos e compensar as reinvidicações não atendidas, pela criação de ilusões" (BACZKO, 1995, p. 321). Para chegar a esse fim, utilizase da moderna arte tecnológica de massas, chamadas por Walter Benjamin de "estetização da política" (BOLLE, 1994, p. 230).

A estatização da vida política se torna ainda mais violenta quando impõe às massas o culto a um chefe, como aconteceu na Itália, com Mussolini, ou na Alemanha, com Hitler. No Brasil, o integralismo vai ter na figura de Plínio Salgado o seu grande líder. Por meio de propagandas, rituais, mitos e símbolos, a AIB vai atingir o imaginário de uma parcela da população brasileira. Por meio do controle "[...] do imaginário social, da sua reprodução, difusão e manejo, assegura em graus variáveis uma real influência sobre os comportamentos 
e as atividades individuais e coletivos, permitindo obter os resultados práticos desejados, canalizar as energias e orientar as esperanças" (BOLLE, 1994, p. 230).

A arte fascista foi buscar modelos nas experiências legitimadas, ao longo dos séculos, no modelo de duas "massas artificiais": exército e igreja. "[...] uma das técnicas para dar às massas uma expressão é o enaltecimento do cotidiano por meio de espetáculos, com as massas e para as massas, revestindo-os de um caráter solene, como nos desfiles triunfais" (BOLLE, 1994, p. 220), criando-se uma esfera pública ritualística. Esses partidos procuravam apresentar-se como uma religião secular. Assim, nesse período, a "[...] história e política são transformadas em fenômenos ao mesmo tempo estéticos e ritualísticos" (FREITAS, 1998, p. 36).

Benjamin, ao fazer a crítica da "estetização de política", por parte do fascismo, possibilitou-nos compreender as contradições da sociedade burguesa. Esse autor propôs a "politização da arte", como uma estratégia de tornar visível o conceito fascista de cultura, com seus mecanismos de mistificação e ritualização. Via na obra de arte tecnológica de massa uma função emancipadora, mas percebeu também "[...] nos meios de comunicação de massa, na esfera pública como um todo, um processo inverso" (FREITAS, 1998, p.36). Com o progresso tecnológico, houve uma regressão, uma restauração do culto à magia. Isso pode ser caracterizado como a modernidade reacionária.

Após essas considerações sobre a "estetização da política" por parte do fascismo, levanta-se uma questão: Como as estratégias de "estetização da política" por parte do fascismo encontrarão ressonância na política brasileira, especificamente na propaganda integralista?

\section{A propaganda integralista nos anos de 1930}

Foi nas ruas e nas praças das cidades que os rituais, os mitos e toda a simbologia integralista se tornaram visíveis a toda a sociedade; em consequência, atraíam novos militantes. Várias estratégias eram colocadas em prática no sentido de unificação, padronização e uniformização do movimento. Para que isso se concretizasse, eram previstas normatizações para as concentrações, bandeiras, trajes, congressos e conclaves, cultos cívicos, visitas e atos sociais, viagens, transportes e hospedagens de integralistas, assim como para os papéis oficiais e a correspondência entre os "camisas-verdes". 
Além das manifestações na rua, eram organizadas as festas integralistas, a vigília da nação, a noite dos tambores silenciosos e as Matinas de abril. Estas deveriam ocorrer na mesma hora em todos os núcleos estabelecidos no País. Nessas cerimônias, pontos da doutrina eram veiculados, como, por exemplo, a "[...] ideia de que no integralismo residia a salvação nacional, o da representação do integralista como grande construtor da pátria e da inexorabilidade da vitória integralista" (CAVALARI, 1999, p. 181). Os falecimentos, casamentos e batizados de integralistas eram realizados por meio de uma cerimônia estabelecida pela doutrina da AIB.

Posto isso, destacam-se os vários momentos em que as ruas e as praças das cidades constituíam-se em espaços de propaganda e manifestação dos rituais e simbologia integralista. As viagens realizadas pelo chefe nacional deveriam ser organizadas pelo chefe provincial e pelo secretário assistente da chefia nacional. Estes estabeleciam o roteiro, os meios de locomoção e as pessoas que comporiam a comitiva. A fim de não demonstrar fragilidade do movimento e ao mesmo tempo mostrar a importância do líder, "[...] o chefe nacional só aceitaria o convite para visitar uma cidade desde que fosse possível ali se concentrarem, no mínimo, mil 'camisas-verdes' e, em se tratando de capital, o número exigindo era cinco mil integralistas" (CAVALARI, 1999, p. 201).

Se essas exigências não fossem atendidas, não poderiam ser realizadas recepções festivas e a viagem assumiria somente um caráter de inspeção. Nas cidades que fossem visitadas pelo chefe nacional, deveriam estar presentes, uniformizados, todos os integralistas, "Blusas Verdes" e "Plinianos". Além de estarem uniformizados, deveriam se apresentar em formação atlética. Para a chegada do chefe nacional, fosse ela nas estações de trem, nos portos e aeroportos ou nas entradas de cidades, tudo deveria estar previamente organizado. A maior autoridade presente "exclamaria: Integralistas! Ao chefe nacional, três anauês. Os presentes responderiam: anauê, anauê, anauê" (CAVALARI, 1999, p. 202). Logo após, seria cantado o hino integralista - Avante.

Terminada a cerimônia de recepção, o chefe nacional e sua comitiva seriam levados para o hotel ou para a casa onde ficariam hospedados, sendo acompanhados por todos os integralistas presentes. Nesse momento, as ruas das cidades eram tomadas pelos "CamisasVerdes", provocando, ao mesmo tempo, a simpatia e a adesão de outros membros, como 
também a ira dos adversários. A organização das festas e as visitas a núcleos ou a instituições da AIB e os atos sociais deveriam ser programados de modo que o chefe nacional não permanecesse no local mais que uma hora. Sua permanência em uma cidade era anunciada com a hasteamento da bandeira integralista, na sede do núcleo. $\mathrm{Na} \mathrm{"[...]} \mathrm{sala}$ principal da sede ou na parte exterior, eram afixados os seguintes dizeres: esta cidade é hoje capital do integralismo, porque está presente o chefe nacional" (CAVALARI, 1999, p. 205).

Em localidades onde havia núcleos integralistas, em datas comemorativas, como a Proclamação da Independência, da República etc., e em dias de festas religiosas, também eram organizados desfiles pelos integralistas. O integralismo usava de todos os recursos simbólicos possíveis para atrair adeptos. "Grandes massas de camisas-verdes marchando ao som de hinos patrióticos e ao grito 'Anauê!'; desfiles grandiosos, em que a ordem e a disciplina impressionavam" (BERTONHA, 2003, p. 65-66), além das reuniões públicas de grande comoção em homenagem aos integralistas mortos em defesa do movimento.

Toda a simbologia e os rituais de padronização e de unificação do integralismo, além de serem responsáveis por criarem, junto com os militantes, a mística do movimento, configuravam-se também em uma estratégia de arregimentação de novos adeptos. Desempenharam uma dupla função para a AIB, pois unificavam e arregimentavam.

Visando à uniformidade de pensamento e de comportamento, entendida como fundamental para a consolidação e a difusão do movimento, criou uma "legislação" especialmente para este fim: os protocolos e rituais. O integralista tinha como dever conhecer e submeter-se a essa legislação sem questioná-la. "Todas as autoridades integralistas são obrigadas a conhecer, cumprir e fazer cumprir os presentes protocolos e rituais em todos os seus pormenores" (PROTOCOLOS..., [entre 1957 e 1961], p. 76).

Nada escapava nesses protocolos e rituais, que tinham como objetivo: "Codificar os dispositivos gerais e mais importantes de seus regulamentos e estabelecer normas, fórmulas e usos que regulem os atos públicos e os cerimoniais integralistas e bem assim fixar honras, regalias, direitos e deveres relativos a todas as autoridades" integralistas (CAVALARI, 1999, p. 164).

Todos os cerimoniais e atos públicos organizados pela AIB eram normatizados em legislação. As atividades de que os integralistas participavam, os cultos cívicos, as festas 
religiosas, os desfiles e as reuniões públicas seguiam todo um ritual estabelecido pelas diretrizes da legislação da AIB. Nesses momentos, as ruas e as praças da cidade eram tomadas pelos integralistas, constituindo-se em um espaço de propaganda do movimento. ${ }^{4}$

Exemplo do exposto foi a realização do I Congresso Meridional Integralista, ocorrido em Santa Catarina na cidade de Blumenau, em outubro de 1935

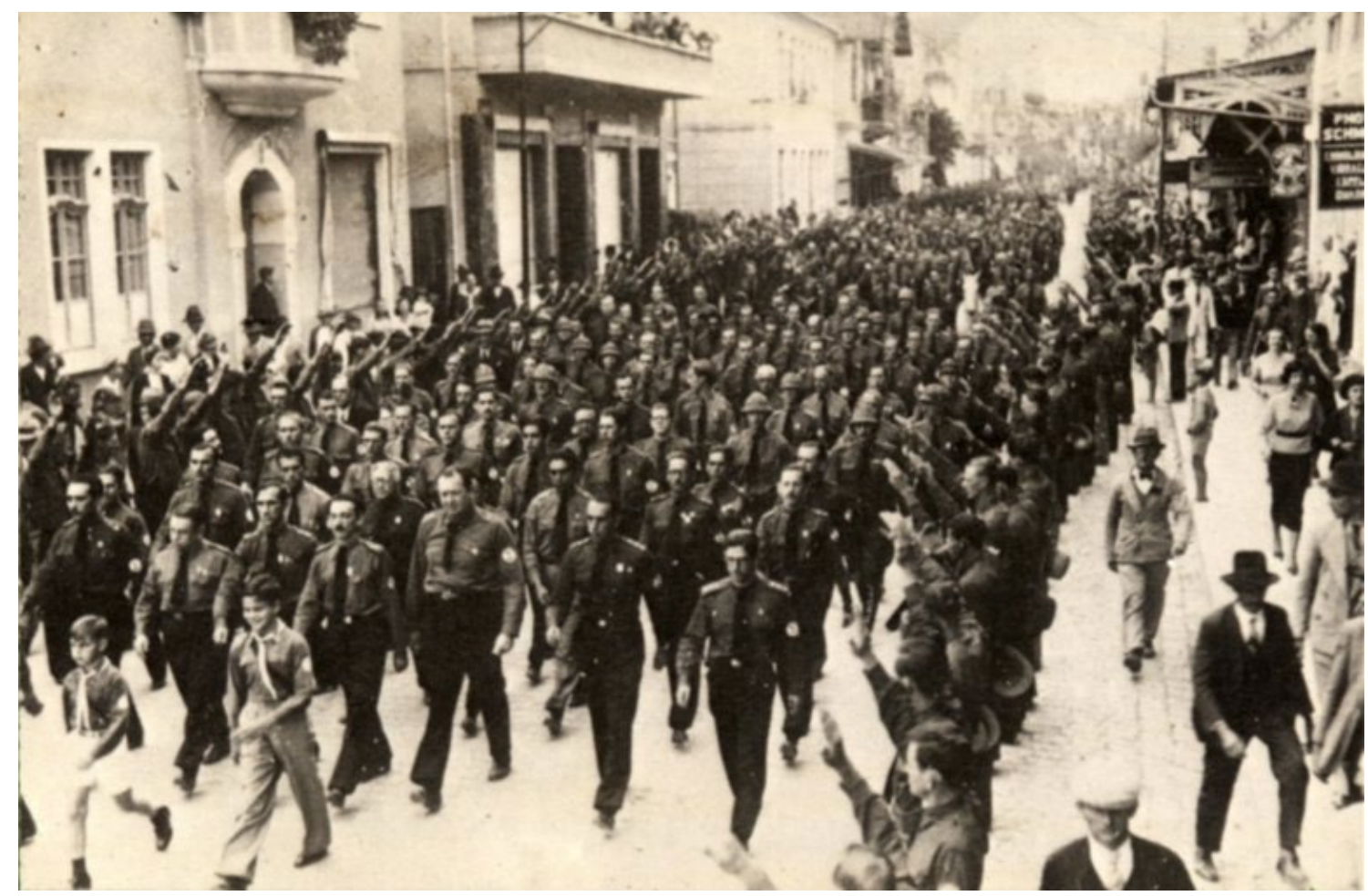

Fonte: Zanelatto (2012, p. 82)

No Congresso Integralista realizado em Blumenau, o jornal Blumenauer Zeitung, que fez a cobertura do evento, relatava que a cidade estava colorida com milhares de camisasverdes. "O tempo não ajudou, mas Blumenau pode considerar o domingo passado como um dia de massas, que nunca tinha ocorrido e que tão logo não acontecerá novamente" (BLUMENAUER-ZENITUNG, 8; 10 out. 1935). O articulista do jornal Anauê descreveu como foi o congresso: "O espetáculo foi maravilhoso e por mais que se queira descrever torna-se

${ }^{4}$ Estudos mais recentes sobre a simbologia e rituais integralistas podem ser encontrados em: Gonçalves e Tanagino (2012), Fagundes (2012) e Athaides (2012). 
impossível, bastará, porém dizer, que esses dias, jamais serão esquecidos". Enfatizava também o disciplinamento dos integralistas durante o congresso, pois "a polícia não teve nenhum trabalho porque os integralistas deram uma demonstração de ordem, disciplina e fé nos grandiosos destinos do nosso amado Brasil". Quanto ao desfile, observou que "40.000 homens desfilaram diante do chefe nacional e esse desfile foi assistido por alguns milhares de pessoas que ali se encontravam para de fato, verem se o integralismo era como dizia" (ANAUÊ, Joinville, ano II, n. 8, 5 out. 1935).

A realização do congresso contribuiu ainda mais para a expansão da AIB em Santa Catarina. O grande número de participantes, vindos de todo o país e das várias regiões do estado, a grande mobilização dos núcleos para organização do Congresso, o grande desfile, e todos os rituais e toda a simbologia contribuíram para aumentar o entusiasmo dos integralistas, que, ao voltarem para seus núcleos, intensificaram o trabalho de organização do sigma e ampliaram o número de adeptos. Isto pode ser constatado no resultado das eleições municipais de 1936 - os integralistas elegeram 8 prefeitos, 72 vereadores e dezenas de Juízes de Paz (ZANELATTO, 2012). "Os integralistas receberam 70\% dos votos no município de Blumenau" (GERTZ, 1987, p. 114), cidade que sediou o Congresso Integralista.

Cabe destacar que todos os eventos integralistas eram anunciados antes de ocorrerem, recebiam a cobertura durante o acontecimento, e amplamente divulgados pela rede de propaganda integralista organizada em âmbito nacional, nos estados e municípios onde os integralistas tinham núcleos e subnúcleos. Através dos jornais e do rádio anunciavam seus eventos, convocavam seus militantes para organizar e participar, divulgavam sus componentes ideológicos, popularizavam a doutrina produzida pelas lideranças do movimento e apresentavam as discussões dos acontecimentos políticos ocorridos em âmbito nacional e internacional (GONÇALVES; SIMÕES, 2019, p. 21).

\section{Plínio Salgado, a constituição da AIB e a conexão com o neointegralismo}

Antes dos episódios que conduziram Getúlio Vargas ao poder, em 1930, Plínio Salgado viaja para a Europa, onde teve a oportunidade de meditar sobre a política brasileira e de conhecer boa parte da literatura política que circulava no Velho Mundo naquele 
momento. Mais importante, porém, foi a sua passagem pela Itália, onde conheceu de perto o fascismo, que o impressionou e estimulou a pensar na criação de algo semelhante no Brasil.

De volta ao Brasil, em São Paulo, teceu críticas ao movimento que elevou Vargas ao poder, considerando-o um perigo liberal democrático. Em 1931, fundou o jornal $A$ Razão, onde, diariamente, apresentava editoriais que davam visibilidade à sua doutrina política. Nesse momento, contraditoriamente, também passou a apoiar o movimento de 1930 , dirigindo ao presidente Vargas notas diárias intituladas "Diretrizes à Ditadura". Plínio Salgado argumentava que o movimento de 1930 implodiu a democracia de fachada que predominava até então. Mesmo assim, Vargas não abriu espaço para Plínio em seu Governo. "Ao contrário, o jornalista de A Razão foi solenemente desconsiderado" (TRINDADE, 1974, p. 18).

A eclosão do movimento de 1932, em São Paulo, articulada pelo Partido Republicano Paulista (PRP), acusou Plínio Salgado de correligionário de Vargas. Isso levou ao empastelamento do jornal $A$ Razão. A partir de então, Plínio Salgado passou a idealizar uma ação política que fosse capaz de envolver as massas em torno de um projeto nacional. Acreditando que naquele contexto o clima político brasileiro estava propício a aceitar suas ideias, fundou, em 1932, a Sociedade de Estudos Políticos - SEP, que passou a sistematizar o conteúdo de sua doutrina. No mesmo ano, lançou o manifesto que criou a Ação Integralista Brasileira - AIB. É importante ressaltar que, no Brasil, já existia "[...] uma série de organizações de caráter fascista, como a Legião Cearense de Trabalho, a Ação Social Brasileira, a Ação Imperial Patrianovista e a Legião Três de Outubro" (TRINDADE, 1974, p. 18). É bem possível que, além dessas, outros grupos de caráter fascista estivessem espalhados pelo Brasil.

As organizações políticas autoritárias geralmente se estruturam hierarquicamente e criam estratégias para enquadrar eficazmente seus militantes.

A organização integralista, entretanto, supera esta função meramente estrutural: além da estrutura vertical e rígida, sob o controle de organismo de enquadramento e socialização ideológica, a AIB incorporou uma nova dimensão capaz de transformar a organização na pré-figuração do Estado Integral. O tipo de organização, as relações entre o chefe e os diversos órgãos estabelecem as bases de uma estrutura estatal. Portanto, a organização da AIB é não somente um meio eficaz voltado para a ação política, mas um instrumento da elaboração e experimentação, em escala reduzida, do Estado Integralista (TRINDADE, 1974, p. 18). 
No manifesto de outubro de 1932, encontram-se as ideias-força do Integralismo: a inspiração cristã, na concepção de universo e de homem; o nacionalismo (anticapitalista e anticomunista); o princípio da autoridade, que envolve hierarquia, confiança e respeito; a crítica à organização dos partidos políticos; a questão social; a família e a nação, vinculados a um Estado forte; o município como conjunto das famílias e célula da nação; e, finalmente, o Estado Integral. Sintetizando, podemos dizer que o manifesto de 1932 propõe o municipalismo, o sindicalismo corporativista, o antifederalismo, o nacionalismo tradicional e espiritualista voltado para a modernização a partir dos instrumentos proporcionados pelo Estado "revolucionário" e o estado integralista (TRINDADE, 1974).

No contexto de ausência de uma identidade nacional, o integralismo apresentava-se como o movimento que despertaria a nação em busca de sua identidade. Também apresentava um programa que passaria pela criação da autoridade e do espírito de disciplina com a organização de uma hierarquia social, partindo da família e do município, passando pelo sindicato e pela corporação, alcançando as regiões e chegando ao topo do Estado e à sua burocracia. A nação era desenhada em miniatura na organização do partido, antecipando a forma que deveria assumir (CHAUÍ, 1978).

Mas como o discurso integralista dos anos 30 foi sendo apropriado décadas seguintes para que se configura-se em uma cultura política? Em 1937, com o golpe de estado que colocou Getúlio Vargas no poder, os partidos políticos foram extintos, entre eles o integralismo. No ano seguinte, em 11 de maio de 1938, foi articulada uma revolta, a fim de derrubar Getúlio Vargas - o ensaio golpista dos integralistas constituiu-se em um ataque ao Palácio da Guanabara e a alguns alvos civis e militares, resultando na prisão de dezenas de militantes (SILVA, 1971).

Após o fim do regime autoritário de Getúlio Vargas, os integralistas voltaram a se organizar em seu partido político - Partido de Representação Popular (PRP) - e disputaram eleições em todos os níveis. (CALIL, 2001). Mesmo não conseguido o grau de popularidade alcançado pela A.I.B., obteve resultados político-eleitorais muito mais expressivos elegendo Governadores, Senadores, Deputados Federais e Estaduais e uma quantidade expressiva de Prefeitos e Vereadores. Nos pleitos disputados entre 1945 a 1962 o PRP elegeu 26 deputados federais e 97 deputados federais (CALIL, 2011). Em Santa Catarina, elegeram 
governador Jorge Lacerda e Plínio Salgado concorreu à Presidência da República (ZANELATTO, 2012).

\begin{abstract}
Além do PRP o Integralismo criou outras organizações, de âmbito nacional ou regional: Instituto Brasileiro de Cultura, Guanabara Football Club, União Operária e Camponesa do Brasil, Confederação dos Centros Culturais da Juventude, Associação Cívico- Cultural Minuano, etc. Também nessa fase, o Integralismo teve os seus periódicos como, por exemplo, os jornais "Idade Nova" e "A Marcha" e a revista "Avante!" (VASCONCELLOS, 2020, par. 15).
\end{abstract}

Com o golpe de 1964, que instalou a ditadura civil-militar, vários militantes integralistas apoiaram o regime, entre eles Plínio Salgado. Desde 1930 até 1975, Plínio Salgado (ano de morte do líder integralista) consolidou-se como o principal referencial e articulador do integralismo. "Residia em Salgado a possibilidade de uma articulação dos integralistas, ainda esperançosos em um porvir de glória para a doutrina do Sigma" (CALDEIRA NETO, 2012, p. 153). Entretanto, observa-se baixa movimentação integralista no contexto da ditadura civilmilitar. Infere-se que essa baixa movimentação decorreu dos limites impostos pelo regime militar. Uma efetiva organização integralista pós-1975 vai ocorrer somente durante o processo de abertura política da ditadura com a criação em São Paulo da Casa Plínio Salgado (CPS), em 10 de outubro de 1981 (CARNEIRO, 2007, p. 230).

Destarte, o fenômeno neointegralismo aparece após a morte de Plínio Salgado. Eram organizações, grupos e mesmo indivíduos que buscavam reorganizar o integralismo. Portanto, a partir da morte do líder integralista, foi se configurando "[...] um campo aberto para disputas de poder e, ainda, o surgimento de novas compreensões e/ou 'modernizações' da ideologia integralista para os tempos mais recentes, aspectos intrinsecamente relacionados" (CALDEIRA NETO, 2012, p. 153).

Assim, no fim dos anos 1970, ocorreram tentativas de organizações neointegralistas, que foram efêmeras. No contexto de abertura política, houve outras tentativas de rearticulação dos integralistas, mas sem muito sucesso. Ocorreu a aproximação de exmilitantes, novos militantes e também com os skinheads. Destaca-se, aqui, a criação, em 1985, da Ação Nacional Brasileira, idealizada pelo antigo membro do PRP - Anésio de Lara Campos Júnior - que buscou articulação com vários grupos de direita, organizados no Brasil (DREIFUSS, 1989). 
Na década de 1990, os vários grupos que estavam articulados em várias regiões do País, mas que até então viviam isolados, passaram a se comunicar via internet, a qual se configurou em um diferencial na comunicação entre os integralistas. "Em sua grande maioria jovens - põem-se a divulgar suas ideias, fotos e vídeos em sites, blogs e redes sociais. Os indivíduos e grupelhos que existiam isolados sem nenhuma representação passam a travar contatos entre si e passam a fazer reuniões regionais e nacionais" (DOTTA, 2012, p. 13).

A década de 1990 marca, ainda, a mudança na produção historiográfica sobre o integralismo. Ocorreu um processo de renovação a partir da incorporação de "novos problemas" e do uso de "novas abordagens". As produções anteriores receberam status de obras clássicas, em especial "as produções de Hélgio Trindade, Marilena Chauí, René Gertz, José Chasin, Gilberto Vasconcellos, Hélio Silva, Ricardo Benzaquen de Araújo, Carla Brandalise, Ivan Alves, entre outros" (CARNEIRO, 2012, p. 11).

Assim, o processo de rearticulação do integralismo/neointegralismo levou à constituição de diversas correntes espalhadas pelo País, concentradas em especial no Sul e no Sudeste, que buscavam legitimar-se como verdadeiros herdeiros do integralismo dos anos de 1930. Segundo Carneiro (2012, p. 151-153):

Com a entrada dos anos 80 , tentou-se a reorganização em formas de associações, que pretendiam reviver a antiga prática integralista de doutrinação por encontros e cursos específicos. Dentre estes, o mais importante na reorganização do integralismo foi o Centro Cultural Plínio Salgado, localizado em São Gonçalo, Rio de Janeiro. Seu fundador e mantenedor era o advogado Arcy Lopes Estella [...] na juventude um membro da militância integralista na década de 1930. Durante a segunda metade da década de 1990, Arcy manteve viva a ideia de união do movimento, organizando em sua caderneta a rede de contato dos que defendiam a permanência da memória integralista, desde velhos a novíssimos militantes. Alguns grupos nacionalistas, mas não necessariamente seguidores diretos do integralismo, também frequentavam o Centro Cultural Plínio Salgado. Alguns deles pertencem ao movimento "Carecas do Rio". Atualmente, este grupo mantém estreita ligação com o movimento, considerando-se parte dele, mas com certa independência em relação aos três grupos mais expressivos, a Frente Integralista Brasileira (FIB), o Movimento Integralista Linearista do Brasil (MIL-B) e a Ação Integralista Revolucionária (AIR). [...] $O$ apadrinhamento da velha militância daria aos "novos" a necessária ligação física com o pensamento de Salgado. Os debates principais juntamente se davam e ainda se dão sobre o modo de reorganização do movimento. Alguns apoiam a reorganização como Partido, outros defendem que a essência integralista é antipartidária, pois a existência de partido faz parte da essência da democracia liberal que abominam.

Como exposto na citação acima, na virada do século e neste novo século, os integralistas/neointegralistas voltaram a se organizar, utilizando-se, em grande medida, dos 
discursos da década de 1930, com seus membros provenientes dos setores médios, e utilizando-se da internet como veículo para divulgar sua ideologia e arregimentar adeptos. Destaca-se como exemplo o Manifesto Integralista publicado em 2001 pelo Núcleo Integralista de Foz do Iguaçu. Nele, o discurso neointegralista está muito bem alinhado às ideias integralistas dos anos de 1930, mas busca também estar atento e incorporar questões vivenciadas neste novo século (CENTRO DE ESTUDOS E DEBATES INTEGRALISTAS, 2004).

\begin{abstract}
O movimento vem atuando em diversas frentes. Uma delas é a utilização da Internet como um dos veículos de comunicação dos ideais neointegralistas. O conteúdo dos sites é constituído de textos de integralistas ilustres - como Plínio Salgado, Miguel Reale e Gustavo Barroso - e de novos integralistas, abordando assuntos atuais do Brasil e do mundo, apresentando as propostas e a doutrina neointegralista. Os pontos que aparecem nos textos são: críticas ao neoliberalismo e à globalização; críticas ao capitalismo liberal e à internacionalização da economia brasileira; rejeição dos movimentos de cunho esquerdista - como, por exemplo, o MST $\square$, resvalando para o anticomunismo; e defesa do nacionalismo, da pátria, da família e da moral cristã (REIS, 2007, p. 144).
\end{abstract}

Os neointegralistas não possuem uma organização centralizada nem se constituem em um movimento de grande popularidade como outrora foi o Integralismo. Vários de seus membros fazem parte dos quadros integralistas dos anos de 1930, por descendentes de velhos integralistas, mas a maioria e constituída por jovens "que veem a doutrina e as propostas políticas integralistas como uma solução para a falta de perspectiva causada pelo modelo de desenvolvimento excludente em vigor no Brasil, resultante das práticas neoliberais e da globalização" (REIS, 2007, p. 114).

No mesmo ano (2001) foi fundado o Centro de Estudos e Debates Integralistas (CEDI) e seu informativo, tinha como editor responsável Marcelo Mendez; redator chefe, Flávio Silva; e jornalista responsável, Arcy Estrella. ${ }^{5} \mathrm{O}$ "Cedi foi um aparelho privado de hegemonia para congregar intelectuais chauvinistas e difundir a ideologia do Sigma" (BARBOSA, 2015, p. 213).

Cabe destacar os dois ${ }^{6}$ grupos mais expressivos, herdeiros do integralismo neste século, e suas diferenças: Movimento Integralista e Linearista Brasileiro (MIL-B) e a Frente Integralista Brasileira (FIB).

\footnotetext{
${ }^{5} \mathrm{O}$ boletim do Cedi constituiu-se em uma fonte importante para a compreensão da efêmera, mas intensa atuação de Marcelo Mendez e sua contribuição para a continuidade do integralismo.

${ }^{6}$ Havia também um terceiro grupo a Ação Integralista Revolucionária (AIR), mas que não existe há cerca de uma década, desde a oficialização da retirada de seu site da internet.
} 
Em 2004, foi fundado em Campinas, São Paulo, o Movimento Integralista e Linearista Brasileiro (MIL-B), que defendia a reinterpretação da ideologia integralista, denominada Linearismo. Foi criado por Cássio Guilherme Silveira, que preside a entidade. Servidor público federal e sobrinho de um ex-integrante da AIB, Cássio Guilherme Silveira conheceu pessoalmente Plínio Salgado e comanda as ações do MIL-B, o qual, além de reproduzir o discurso integralista, contrapõe-se à figura de Papai Noel e defende o uso do Vovô Índio. Para ele, a família real portuguesa sofreu um golpe com a Proclamação da República, por isso, defende a sua volta (CORREIO POPULAR, 6 jan. 2013).

Em 2015, foi realizada a XI edição do Congresso Nacional Integralista e Linearista. $\mathrm{Na}$ abertura do evento, o Presidente Nacional do MIL-B, Cássio Guilherme Silveira, fez a saudação ao Chefe Nacional, Plínio Salgado, e discursou sobre o momento atual em que vive o Brasil. Foram exibidos filmes e documentários sobre a situação atual do Brasil e sobre o futuro do País. Defenderam a ampliação da divulgação da doutrina e organizaram estratégias para a ação em 2016, dentre as quais estava a de eleger um vereador para a Câmara de Vereadores de Campinas.

Em texto publicado em sua página intitulado "A necessidade de atualizar a doutrina integralista" o Mil-b propôs algumas atualizações. O texto evidenciava a necessidade do movimento de se atualizar para enfrentar os desafios do século XXI, e entre elas destacam-se

Não estamos mais na década de 30 . Várias questões foram colocadas no contexto
político, sociológico e filosófico do mundo, em particular do nosso país. Fez-se
urgente então os integralistas modernos se debruçarem sobre essas questões e
proporem novos paradigmas concernentes a essa realidade atual. Questões como a
Ideologia de gênero, o direito dos animais e da natureza, a cibernética como forma de
troca de informações na velocidade da luz, a mídia de massa e a população, o papel
da mulher na sociedade, o tecnicismo e o cientificismo, todas essas proposições
precisavam ser enquadradas num novo arcabouço doutrinário e filosófico que
contemplasse as razões e soluções engendrados para o presente e o futuro
(NASCIMENTO, 2020, par. 2).

Entretanto, explicitaram que os três pontos centrais da doutrina dos anos 30 - "a defesa do Nacionalismo Espiritualista, do Modelo Corporativista de governo e do combate ao Capitalismo Liberal e ao Comunismo permaneceram intactos, como os estruturou principalmente o Chefe Nacional Plínio Salgado" (NASCIMENTO, 2020, par. 2). 
Permaneceram também outros pontos da doutrina, mas com novas definições, como por exemplo, o lema DEUS, PÁTRIA E FAMÍLIA. Em relação a Deus se opõe ao cristianismo atual, explicam que "Nosso Deus é aquele que combate o materialismo e está vigilante todo tempo com a existência do mundo. Portanto, o nosso Deus não tem nada a ver com esse livro chamado bíblia, que representa sim um deus judaico sanguinário e pirracento" (NASCIMENTO, 2020, par. 4). Quanto à Pátria explicam que "é aquela formada por nossos amigos integralistas e linearistas. Não temos, pois, qualquer compromisso com tradições de ordem e progresso positivistas e nem com fatores históricos que não coadunam com nosso modo de pensar" (NASCIMENTO, 2020, par. 5). E a família "são igualmente não os objetos consaguíneos, nem parentais, mas todos aqueles que lutam no nosso lado pelos mesmos ideais de liberdade do nosso povo do argentarismo internacional e do materialismo" (NASCIMENTO, 2020, par. 5).

Nas recentes mobilizações ocorridas no Brasil os militantes do Movimento Integralista e Linearista Brasileiro foram para as ruas e fizeram coro com os grupos conservadores pedindo intervenção militar.

\section{Imagem II - Manifestação de neointegralistas pedindo intervenção militar}

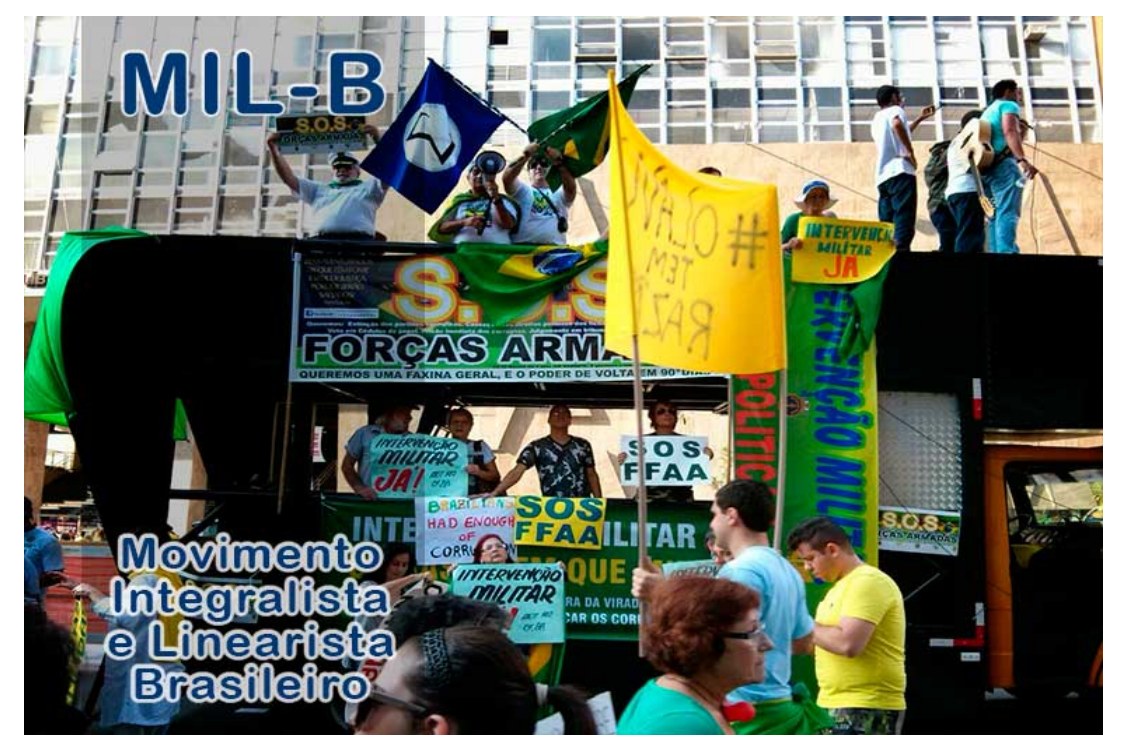

Fonte: (MIL-B, 2021) 
Nestas manifestações, além do pedido de intervenção militar, pediam também o fim do voto universal, dos partidos políticos e da República. Juntamente com outros setores conservadores da sociedade brasileira os neointegralistas questionavam as instituições e o Estado Democrático de Direito.

Imagem III - Manifestação de neointegralista contra instituições da República

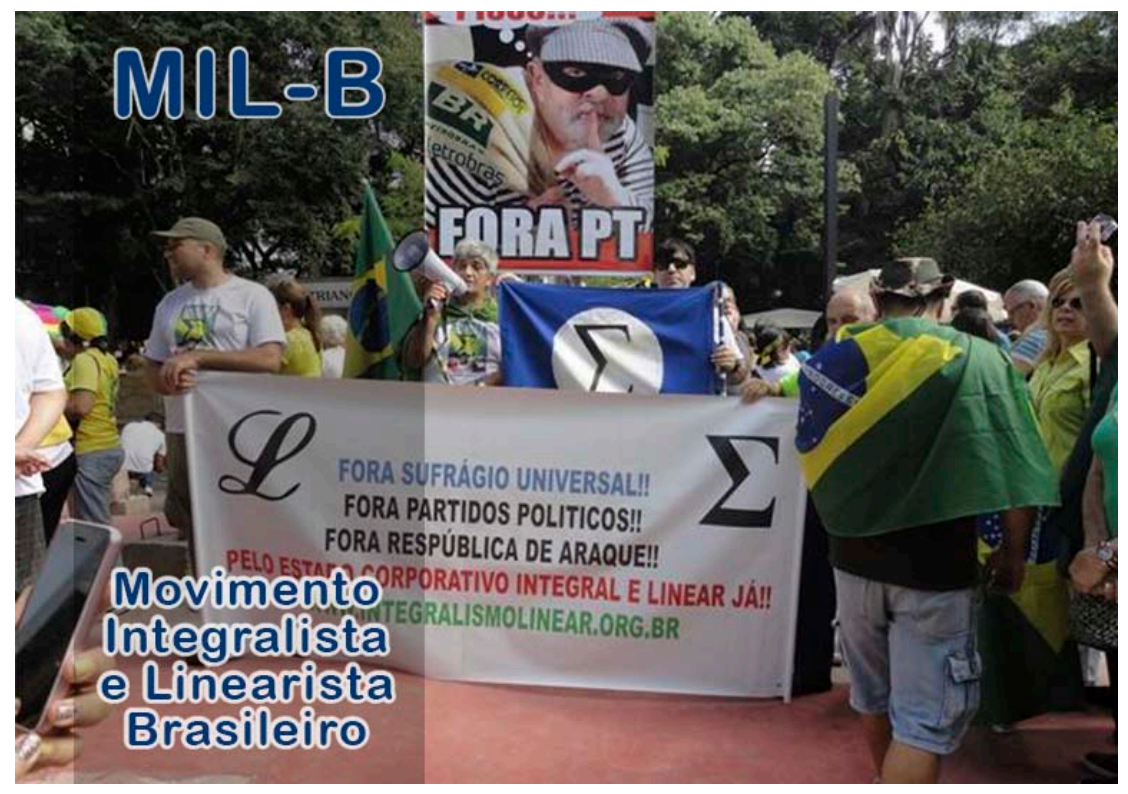

Fonte: (MIL-B, 2021)

A Frente Integralista Brasileira (FIB), que foi fundada na cidade de São Paulo em janeiro de 2005, afirmam que são o único grupo de novos integralistas a defender a manutenção dos postulados integralistas formulados originalmente na década de 1930. Seu primeiro presidente foi Marcelo Baptista da Silveira, que ocupou o cargo desde a criação até 2009. Seu nome teria sido escolhido, pois na época era presidente do CEDI, Centro de Estudos e Debates Integralistas. Entre 2009 a 2020 a direção foi ocupada por Victor Baubuy. Em 14 de março de 2020, foi empossada uma nova diretoria, que passou a ser presidida por Moisés Lima (GONÇALVES; CALDEIRA NETO, 2020).

A FIB é, atualmente, a organização mais representativa dos integralistas, constituída por quatorze núcleos espalhados em nove Estados, com maior concentração em São Paulo. Em seu site, na apresentação, a Frente Integralista Brasileira, expressa que "tem por finalidade promover movimentos culturais, políticos e sociais como forma de resgate da 
herança cultural, cívica, política e ideológica da Ação Integralista Brasileira, principalmente no que se refere à trilogia Deus, Pátria e Família" (APRESENTAÇÃO, 2020, par. 5), expõe ainda que é "um movimento espiritualista, aberto a pessoas de todas as denominações religiosas, desde que sejam respeitados os princípios da moral e dos costumes cristãos e brasileiros" (APRESENTAÇÃO, 2020, par. 6), finaliza a apresentação com seus princípios fundamentais:

\begin{abstract}
Afirmar-se como escola política no sentido de procurar desenvolver uma nova mentalidade nacional, tendo como inspiração os fundamentos do Manifesto de Outubro de 1932;
\end{abstract}

Funcionar como movimento cultural e cívico consoante os ditames do Código de Ética do Estudante, elaborado por Plínio Salgado, em 1946;

Defender o resgate da tradição cristã do povo brasileiro, bem como o resgate e o desenvolvimento da cultura nacional (APRESENTAÇÃO, 2020, par. 7-9, grifo do autor).

Ficam evidenciados divergências entre os grupos neointegralistas na forma como interpretam a doutrina do integralismo dos anos de 1930. Duas questões estão presentes na doutrina integralista dos anos 30, mas foram negadas pelos neointegralistas: "Negação retórica do antissemitismo (embora subsistam críticas aos 'judeus'), bem como repulsa ao fascismo e, sobretudo, ao nazismo (não obstante, o fascismo seja por vezes justificado como tendo sido um 'mal menor' diante do comunismo)" (DOTTA, 2012, p. 13). Aspecto comum aos neointegralistas é o uso da internet para dar visibilidade à doutrina e à história do integralismo. "Na guerra pelo reconhecimento como os 'verdadeiros integralistas', os militantes de ambos os grupos ampliam suas redes de divulgação doutrinária pela internet. São blogs, orkuts, lojas virtuais, sites sobre a história dos líderes e do movimento" (CARNEIRO, 2012, p. 22), os quais se apresentam como meios de comunicação que os neointegralistas do século XXI utilizam para se comunicar na perspectiva de buscar novos adeptos.

Entretanto é preciso destacar que mesmo utilizando intensamente da internet para propagar sua doutrina (imprensa também utilizada intensamente na década de 1930) as praças, os espaços públicos continuam sendo também locais de disseminação da doutrina e arregimentação de militantes. Pode-se afirmar que 2013 marcou o processo de intensa atuação dos neointegralistas nas praças e espaços públicos, mas essa atuação vinha ocorrendo anteriormente em desfiles comemorativos, como por exemplo, a independência, 
em eventos religiosos, nas críticas aos governos do partido dos trabalhadores. Essa atuação fica evidenciada nas imagens/fotografias exposta nos sítios tanto da FIB como do MIL-B.

A partir do exposto entende-se que ficou evidenciado o integralismo como uma cultura política, pois ao longo do século XX e neste século observamos que seus valores, práticas e representações políticas foi ao longo desse tempo mobilizado e permaneceu. Na atualidade os neointegralistas se apropriaram e vem difundindo os pressupostos integralistas da década de 1930 e mesmo que o Movimento Integralista e Linearista Brasileiro e a Frente Integralista Brasileira não tenham um grande número de filiados/adeptos, suas narrativas vêm contribuindo para a permanência de uma cultura política conservadora no país. O integralismo foi o movimento fascista mais "importante" do Brasil (não foi o único) e, portanto, ao difundirem a doutrina integralista dos anos de 1930, os neointegralistas trazem à tona o fascismo. Infere-se ainda que os neointegralistas ao darem maior evidência ao integralismo dos de 1930 objetivam alcançar as glórias daquele passado, pois não se observa em suas narrativas/programa abordarem, remeteram ao PRP que atuou por mais tempo (1945 - 1965) que o integralismo e obteve melhores resultados do ponto de vista eleitoral. Não se observa também evidenciarem a presença/atuação de Plínio Salgado durante a ditadura civil-militar.

\section{Considerações finais}

O que nos interessou foi mostrar como as ruas e as praças das cidades se constituíram em um espaço para a propaganda integralista. Procuramos demonstrar que parte da simbologia e dos rituais integralistas (as grandes concentrações, os desfiles, o civismo, o disciplinamento, o nacionalismo de farda, as demonstrações de patriotismo, etc.) utilizavam as ruas $e$ as praças das cidades como lugar para a sua manifestação e arregimentação. Infere-se que as manifestações de 2013 marcaram o crescimento das ações dos neointegralistas, que saíram às ruas com suas bandeiras, seus símbolos e faixas pedindo o fim dos partidos e a intervenção militar. Esses setores ultraconservadores e reacionários estão sempre à espreita, à espera de uma oportunidade para se manifestar. Se os neointegralistas não elegeram nenhum candidato (eleições de 2014), participaram ativamente das mobilizações, utilizaram ativamente a internet para propagar e popularizar 
sua doutrina que, em certa medida, reverberaram e atingiram significativos setores da sociedade brasileira.

Pode-se afirmar que os setores conservadores conseguiram capitalizar com as mobilizações iniciadas partir de 2013, pois nas eleições gerais de 2014 (mesmo reelegendo a presidente do campo da esquerda) conseguiram eleger uma quantidade significativa de deputados federais, de senadores e também de deputados estaduais de perspectiva conservadora e ultraconservadora, assemelhando-se em muito ao discurso integralista dos anos de 1930. Em 2015, esses setores conservadores promoveram o impeachment/golpe da presidente da República Dilma Rousseff e em 2018 elegeram Jair Bolsonaro para presidência da República.

Mesmo com o fim da Ação Integralista Brasileira, ocorrido com o golpe de Estado em 1937, os partidários do integralismo buscaram, ao longo dos anos, reorganizar-se sob a liderança de Plínio Salgado. Após a morte de sua principal liderança, em 1975, abriu-se um campo de disputa em torno da ideologia integralista, que experimentou algumas mudanças. Os neointegralistas foram se organizando e fundamentando sua retórica na matriz integralista dos anos de 1930, mas incorporando outras interpretações e modernizações. Portanto, o integralismo configura-se em uma cultura política, sua retórica permaneceu no presente (anticomunismo, antiliberalismo, corporativismo, o lema, a simbologia indumentária, bandeiras, o uso da propaganda e dos espaços públicos como canais de divulgação doutrinaria configurando-se em importante elemento dialógico e articulador de aproximações com a sociedade) e inspira projetos políticos de futuro para grupos neointegralista, além de contribuir para sedimentar na sociedade brasileira uma cultura política conservadora.

Nesse período, a sociedade brasileira experimentou profundas transformações (período marcado (1930 a 2018) por conjunturas distintas, ora autoritárias, leia-se Estado Novo - 1937-1945 - e ditadura civil-militar - 1964-1985 -, ora pela abertura política (19451964) e pós-ditadura em diante, mas também pela permanência de uma cultura política conservadora. Portanto, devemos ficar atentos e não esquecer de refletir sempre sobre o que esses grupos representaram e representam para a sociedade. 
Por fim, em tempos de avanço dos setores ultraconservadores, este breve escrito configura-se em uma pequena contribuição e provocação para que outras pesquisas possam aprofundar a temática ou abordar outros aspectos que explicitem a permanência de uma cultura política conservadora no país, dificultando e impedindo a resistência dos movimentos sociais e da esquerda de modo geral.

\section{Fontes}

ANAUÊ. Joinville: [s.n.], 1934-1937.

BLUMENAUER-ZENITUNG. Blumenau: [s.n.], 1881-1938.

CENTRO DE ESTUDOS E DEBATES INTEGRALISTAS. Manifesto Integralista de 2001. Integralismo, Rio de Janeiro, 27 fev. 2004. Disponível em:

http://integralismo.blogspot.com/2015/03/manifesto-integralista-de-2001.html. Acesso em: 18 jan. 2021.

CORREIO POPULAR. Campinas: [s.n.], 1927-.

MANIFESTO Integralista de outubro de 1932. Disponível em: https://www.integralismo.org.br/manifesto-de-7-de-outubro-de-1932/. Acesso em: 18 fev. 2021.

MONITOR INTEGRALISTA, São Paulo: AIB, 1933-1937.

PROTOCOLOS Rituais. In: DÓREA, Gumercindo Rocha (Ed.). Enciclopédia do Integralismo. São Paulo: GRD, [entre 1957 e 1961]. v. 11, cap. 1, p. 76, art. III.

\section{Referências}

APRESENTAÇÃO. Integralismo - Frente Integralista Brasileira, 30 jul. 2020. Disponível em: https://www.integralismo.org.br/apresentacao/. Acesso em: 19 jan. 2021.

ARAÚJO, Ricardo Benzaquen de. Totalitarismo e revolução: o integralismo de Plínio Salgado. Rio de Janeiro: J. Zahar, 1988.

ATHAIDES, Rafael As paixões pelo sigma: afetividades políticas e fascismos. 2012. $304 \mathrm{f}$. Tese (Doutorado em História)-Universidade Federal do Paraná, Curitiba, 2012. Disponível em: https://hdl.handle.net/1884/28288. Acesso em: 18 jan. 2021. 
BARBOSA, Jefferson Rodrigues. Chauvinismo e extrema direita: crítica aos herdeiros do sigma. São Paulo: UNESP, 2015. https://doi.org/10.7476/9788568334683

BACZKO, Bronislaw. Imaginação social. In: Enciclopédia Einaudi. Porto: Imprensa Nacional, 1995. v. 5, p. 321.

BENJAMIN, Walter. A obra de arte na época de suas técnicas de reprodução. São Paulo: Abril Cultural, 1975. Coleção Os Pensadores.

BERSTEIN, Serge. A cultura política. In: RIOUX, Jean-Pierre; SIRINELLI, Jean-François (Org.). Para uma História Cultural. Lisboa: Estampa, 1998. p. 349-363.

BERSTEIN, Serge. Os partidos. In: REMOND, René (Org.). Por uma história política. 2. ed. Rio de Janeiro: FGV, 2003. p. 57-98.

BERTONHA, João Fábio. Fascismo, nazismo, integralismo. São Paulo: Ática, 2003.

BERTONHA, João Fábio. O Integralismo e sua história: memória, fontes, historiografia. Salvador: Pontocom, 2016.

BOLLE, Willi. Fisiognomia da metrópole moderna: representação da história em Walter Benjamin. São Paulo: USP, 1994.

CALDEIRA NETO, Odilon. Neointegralismo e as direitas: entre aproximações e distanciamentos. Locus Revista de História, Juiz de Fora, v. 18, n. 1, p. 147-165, 2012. Disponível em: https://periodicos.ufjf.br/index.php/locus/article/view/20367. Acesso em: 12 jan. 2021.

CALIL, Gilberto Grassi. O integralismo no pós-guerra: a formação do PRP (1945-1950). Porto Alegre: PUCRS, 2001.

CARNEIRO, Márcia Regina da Silva Ramos. Do Sigma ao Sigma: entre a anta, a águia, o leão e o galo - a construção das memórias integralistas. 2007. 415 f. Tese (Doutorado em História Política) - Universidade Federal Fluminense, Niterói, 2007. Disponível em: https://www.historia.uff.br/stricto/teses/Tese-

2007_CARNEIRO_Marcia_Regina_da_Silva_Ramos-S.pdf. Acesso em: 15 jan. 2021.

CARNEIRO, Márcia Regina da Silva Ramos. Uma velha novidade: o integralismo no século XXI. Boletim do Tempo Presente, n. 03, 2012. Disponível em: https://seer.ufs.br/index.php/tempopresente/article/view/4158. Acesso em: 16 jan. 2021.

CAVALARI, Rosa Maria Feiteiro. Integralismo: ideologia e organização de um partido de massas no Brasil (1932-1937). Bauru, SP: Universidade do Sagrado Coração, 1999.

CHAUÍ, Marilena. Apontamentos para uma crítica da Ação Integralista Brasileira. In: CHAUÍ, Marilena; FRANCO, Maria Silvia Carvalho. Ideologia e Mobilização Popular. São Paulo: Paz e Terra/CEDEC, 1978. p. 17-149. 
DOTTA, Renato Alencar. Um esboço necessário sobre a trajetória do integralismo brasileiro - da AIB ao ciberintegralismo (1932 a atualidade). Boletim do Tempo Presente, n. 03, 2012. Disponível em: https://seer.ufs.br/index.php/tempopresente/article/view/4156. Acesso em: 16 jan. 2021.

DREIFUSS, René. O jogo da Direita. Rio de Janeiro: Vozes, 1989.

FAGUNDES, Pedro Ernesto. Morte e memória a necrofilia política da Ação Integralista Brasileira (AIB). Varia História, Belo Horizonte, v. 28, n. 48, p.889-909: jul/dez 2012. https://doi.org/10.1590/S0104-87752012000200019

FREITAS, Marcos César de. O integralismo: fascismo caboclo. São Paulo: Ícone, 1998.

GERTZ, René. O integralismo em Santa Catarina. Revista do Instituto Histórico Geográfico de Santa Catarina, $3^{\mathrm{a}}$ fase, n. 5, p. 16-28, 1984.

GERTZ, René. O fascismo no Sul do Brasil. Porto Alegre: Mercado Aberto, 1987.

GONÇALVES, Leandro Pereira; TANAGINO, Pedro Ivo Dias. Simbologia e sugestão: ideal de homem integral em protocollos e rituaes (1937). Temáticas, Campinas, v. 20, n. 39, p. 181-198, ago./dez. 2012. https://doi.org/10.20396/tematicas.v20i39.11443

GONÇALVES, Leandro Pereira; SIMÕES, Renata Duarte. Entre tipos e recortes: histórias da imprensa integralista. Rio de Janeiro: Autobiografia, 2019. v. 3.

GONÇALVES, Leandro Pereira; CALDEIRA NETO, Odilon. O fascismo em Camisas Verdes: do integralismo ao neointegralismo. Rio de Janeiro: FGV, 2020.

MOTTA, Rodrigo Patto Sá. Culturas políticas na história: novos estudos. Belo Horizonte: Argvmentvm, 2009.

NASCIMENTO, Welson. A necessidade de se atualizar a doutrina integralista. MIL-B, 19 mar. 2020. Disponível em: https://integralismolinear.org.br/a-necessidade-de-se-atualizar-adoutrina-integralista/. Acesso em: 30 maio 2021.

REIS, Natalia. A ideologia do sigma hoje: Neointegralismo, intolerância e memória. História: Questões \& Debates, Curitiba, v. 46, n. 1, p. 113-138, 2007. http://dx.doi.org/10.5380/his.v46i0.11328

REMOND, René (Org.). Por uma história política. 2. ed. Rio de Janeiro: FGV, 2003.

ROLNIK, Raquel. O que é cidade? São Paulo: Brasiliense, 2004.

SILVA, Hélio. Terrorismo em Campo Verde. Rio de Janeiro: Civilização Brasileira, 1971.

TRINDADE, Hélgio. Integralismo: o fascismo brasileiro na década de 30. Porto Alegre: Universidade Federal do Rio Grande do Sul, 1974. 
TRINDADE, Hélgio. A tentação fascista no Brasil: imaginário dos dirigentes e militantes. Porto Alegre: UFRGS, 2016.

VASCONCELLOS, Sérgio de. Cronologia da História do Integralismo. Integralismo | Frente Integralista Brasileira. Página modificada em: 25 ago. 2020. Disponível em: https://www.integralismo.org.br/apendice-historico/. Acesso em: 30 maio 2021.

ZANELATTO, João Henrique. De olho no poder. o integralismo e as disputas políticas em Santa Catarina na era Vargas. Porto Alegre: PUCRS, 2012. 